\title{
Analysis of Potassium Bromate and Hydrocyanic Acid Contents of Commonly Consumed Loaves of Bread and Wheat Flour Samples In Karu,Nasarawa State, Nigeria
}

\author{
Ojo Rotimi Johnson ${ }^{1}$, Kajang Duniya Daniel ${ }^{1}$, Adebayo-Gege Grace Iyabo ${ }^{3}$, \\ Akintayo Christopher Oloruntoba ${ }^{2}$ \\ ${ }^{I}$ (Department of Biochemistry, Faculty of Science and Technology, Bingham University Karu Nasarawa state, \\ Nigeria) \\ ${ }^{2}$ Department of Physiology, College of Medicine and Health Sciences, Afe Babalola University Ado-Ekiti, Ekiti \\ state, Nigeria) \\ ${ }^{3}$ Department of Physiology, Faculty of Basic Medical sciences, College of Medicine Bingham University Karu \\ Nasarawa state, Nigeria)
}

\begin{abstract}
The potassium bromate and hydrocyanic acid contents in commonly consumed fourteen loaves of bread and four most popular wheat flour brands among the bakers in Karu local government of Nasarawa state, Nigeria were assessed for potassium bromate and hydrocyanic acid contents. Potassium bromate in bread samples analyzed ranged between $0.5 \mu \mathrm{g} / \mathrm{g}$ to $8.4 \mu \mathrm{g} / \mathrm{g}$ and $0.83 \mu \mathrm{g} / \mathrm{g}$ to $1.42 \mu \mathrm{g} / \mathrm{g}$ in wheat flour samples. The hydrocyanic acid contents of the bread and wheat flour samples analyzed ranged between 1.510 to 3.676 $\mathrm{mg} / 1000 \mathrm{~g}$ and 0.706 to $1.498 \mathrm{mg} / 1000 \mathrm{~g}$ sample respectively. These results implied that all the loaves of bread and wheat flour brands analysed contained potassium bromate in high quantity above safe level for human consumption and various amount of hydrocyanic acid which however, will not lead to the lethal dose of 35 mg hydrocyanic acid per $\mathrm{kg}$ body weight but there is need for continuous surveillance and enforcement of the ban on the use of potassium bromate in baking industry in this study area by NAFDAC.
\end{abstract}

Keywords: Bread, Hydrocyanic acid, Picric acid, Potassium bromate, Wheat

\section{Introduction}

Bread is an important staple food of many countries of the world especially the African countries, where it is consumed extensively [1]. It is usually made from low protein wheat flour, water and other ingredients which are usually combined with a leavening agent to improve its quality $[2,3]$.The major challenge in both flour milling industry and bakeries is the baking quality of flour, which is determined by the capacity of the dough prepared from it to retain gas. As a result of wide variations in the composition of flour, various supplements or conditioning agents (improvers) are added during mixing and moulding to increase loaf volume, texture and strength [3].

The use of potassium bromate has been a common choice among flour millers and bakers throughout the world because it is cheap and acts as a maturing agent and dough conditioner by oxidizing the sulphydryl groups of the gluten protein in flour into disulphide bridges making it less extensible and more elastic such that it can retain the carbon dioxide gas produced by the yeast. The overall effect is to make bread rise in the oven, increase loaf volume and texture as a result, many bakeries use potassium bromate as an additive to assist in the raising process and to produce a texture in the finished product that is appealing to the public $[3,4]$. Over time, it has been discovered that potassium bromate is toxic and can cause abdominal pain, diarrhoea, nausea, vomiting, kidney failure, oligonuria, anuria, deafness, vertigo, and hypotension, depression of the central nervous system, thrombocytopenia and cancer with other related health problems $[5,6]$. In addition to these, it affects the nutritional quality of bread by degrading the vitamins and essential fatty acid contents of flour [3].Due to its toxic effects the National Agency for Food and Drug Administration and Control (NAFDAC) in Nigeria has banned its further use in bread, but many Nigerian bakers continue to use it in other to enhance their profits [2].

Many plant species produce and sequester cyanogenic glycosides [7] which is toxic to humans leading to vomiting, exacerbate goitre, cretinism in iodine-deficient regions, nausea, dizziness, stomach pains, weakness, headache, diarrhea, paralysis, neurological disorders, Tropical Ataxic Neuropathy (TAN), stunting of children and occasionally, death $[8,9,10]$.The toxic effect is due to the hydrocyanic acid (HCN) released during the hydrolysis of cyanogenic glucosides[11,12,13].

The main objective of this study was to evaluate the potassium bromate and hydrocyanic acid contents in commonly consumed loaves of bread and wheat flour samples in Karu local government of 
Nasarawa state ,Nigeria, as most of these products labels only indicates the nutritional attributes and not their safety which is taken for granted in developing countries.

\section{Materials and Met}

A survey of available loaves of bread and flour samples in karu, Nasarawa state in Northern part of Nigeria, were carried out in bakeries, fast foods outlets, open markets, bus stops and flour distributors' shops in Karu local government. Fourteen different types of bread samples freshly baked and well packaged by their bakers were selected based on their availability and popularity among the majority of the consumers; also four most popular wheat flour brands among the bakers were selected. The bread samples are represented with alphabets while the flour samples are represented by their National Agency for Food and Drug Administration Control (NAFDAC) numbers.

\subsection{Chemicals}

Hydrochloric acid (Sigma chemical Co, St Louis USA), Potassium iodide (BDH, England), Potassium Bromate (Sigma chemical Co, St Louis, USA), Potassium cyanide (Sigma chemical Co, St Louis, USA), Picric acid (BDH, England), Sodium hydroxide (Hopkins and Williams Ltd, England).

\subsection{Determination of potassium bromate in bread and wheat flour samples}

Potassium bromate contents of the bread and wheat flour samples were analyzed using previously reported method [14]. $1.0 \mathrm{~g}$ was weighed out from each bread or wheat flour sample in an electronic weighing balance. This was transferred into a test tube. Ten milliliter $(10 \mathrm{ml})$ of distilled water was added and the mixture was shaken and allowed to stand for $20 \mathrm{~min}$ at $28 \pm 5^{\circ} \mathrm{C} .5 .0 \mathrm{ml}$ was decanted from the test tube into another test tube and $5.0 \mathrm{ml}$ of freshly prepared $0.5 \%$ potassium iodide solution in $0 . \mathrm{IN}$ hydrochloric acid was added. Any colour change was noted. The presence of potassium bromate was indicated by change in colour from light yellow to purple [14]. The absorbance of the sample was taken at $540 \mathrm{~nm}$ in a spectrophotometer (Spectrum Lab 752S). Absorbance of the sample was converted to concentration with reference to Beer's calibration curve previously constructed for potassium bromate using the pure sample.

\subsection{Determination of hydrocyanic acid in bread and wheat flour samples}

The hydrocyanic acid of the samples was determined using the alkaline picrate method with modifications [15].1.0 g of the sample was weighed out from each bread or wheat flour sample in an electronic weighing balance. This was transferred into a $100 \mathrm{ml}$ volumetric flask. Ten milliliter $(10 \mathrm{ml})$ of distilled water was added; the mixture was shaken and allowed to stand for 30 mins at $28 \pm 5^{\circ} \mathrm{C}$. The supernatant was collected and measured with measuring cylinder and was used for cyanide analysis. For this analysis, $1 \mathrm{ml}$ of the sample was pipette into test tube followed by $1 \mathrm{ml}$ of $0.04 \mathrm{M}$ picric acid and $1 \mathrm{ml}$ of $0.75 \mathrm{M} \mathrm{NaOH}$. The solution in the test tube was mixed and incubated for 15 minutes at room temperature. In this method, hydrocyanic acid ( $\mathrm{HCN})$ released during hydrolysis of the cyanogenic glycosides reacts with picric acid to produce a yellow colored solution. Sodium hydroxide preserves the $\mathrm{HCN}$ released. Colour intensity was measured spectrophotometrically at the wavelength of $540 \mathrm{~nm}$. The same process above was used for all other samples and the reference standard. Calculation:

$\mathrm{CONC}_{\mathrm{HCN}}=\frac{\mathrm{O}_{\mathrm{TEST} \times}}{\text { O.D } \mathrm{STD}} \quad \frac{\mathrm{CONC}_{\mathrm{STD}} \times \text { Volume obtained }}{\text { Volume of sample used }} \times 1000$

O.D $=$ Optical Density/Absorbance

$\mathrm{STD}=$ standard

Conc $=$ Concentration

\subsection{Statistical analysis}

The data are expressed as mean $\pm \mathrm{SD}$. Readings were compared using the one-way ANOVA analysis and Independent sample test. Statistical analysis was performed using SPSS (Version 17). A level of $p<0.05$ was considered to be significant

\section{Result and Discussion}

Potassium bromate in bread samples analyzed is shown in (Table 1). The sample with the least concentration of potassium bromate is sample $\mathrm{G}(0.5 \mu \mathrm{g} / \mathrm{g})$ while the highest concentration was found in sample $\mathrm{N}(8.4 \mu \mathrm{g} / \mathrm{g})$. These levels are higher than $0.02 \mu \mathrm{g} / \mathrm{g}$, permitted by the US Food and Drug Agency (FDA) [17] but lower than the levels permitted by China $(50 \mu \mathrm{g} / \mathrm{g})$ and Japan $(10 \mu \mathrm{g} / \mathrm{g})$. These high concentrations are in 
agreement with other findings which showed that most loaves of bread in Nigerian cities have high potassium bromate contents [3,16, and 18].

Table 1: Concentration of potassium bromate $(\mu \mathrm{g} / \mathrm{g})$ in bread samples

\begin{tabular}{|c|l|}
\hline Bread samples & Potassium bromate $(\mu \mathrm{g} / \mathrm{g})$ \\
\hline A. & $7.4 \pm 0.01^{\mathrm{c}}$ \\
\hline B. & $2.4 \pm 0.06^{\mathrm{b}}$ \\
\hline C. & $6.0 \pm 0.01^{\mathrm{c}}$ \\
\hline D. & $7.2 \pm 0.01^{\mathrm{c}}$ \\
\hline E. & $6.4 \pm 0.25^{\mathrm{c}}$ \\
\hline F. & $6.3 \pm 0.17^{\mathrm{c}}$ \\
\hline G. & $0.5 \pm 0.05^{\mathrm{a}}$ \\
\hline H. & $8.3 \pm 0.02^{\mathrm{c}}$ \\
\hline I. & $6.0 \pm 0.18^{\mathrm{c}}$ \\
\hline J. & $4.2 \pm 0.01^{\mathrm{b}}$ \\
\hline K. & $3.2 \pm 0.01^{\mathrm{b}}$ \\
\hline L. & $5.2 \pm 0.21^{\mathrm{c}}$ \\
\hline M. & $6.5 \pm 0.03^{\mathrm{c}}$ \\
\hline N. & $8.4 \pm 0.12^{\mathrm{c}}$ \\
\hline O. & $0.9 \pm 0.04^{\mathrm{a}}$ \\
\hline
\end{tabular}

Results are expressed as mean \pm standard deviation of three observations. Values with similar alphabet do not show significant differences at $\mathrm{p}<0.05$

The flour samples (Table 2) from which most of the bakeries in the study areas claimed to have baked their loaves of bread from have lower Potassium bromate levels compare to the bread samples and it is a known fact that potassium bromate evaporates during the baking process. The high amount of potassium bromate found in the analyzed bread samples is an indication that the compliance with NAFDAC ban on the use of potassium bromate in bread is poor and there is high dietary exposure to potassium bromate through bread consumption in this area which is an indication that the regulatory agency need to step up their surveillance and enforcement of this rule. Potassium bromate added to bread is harmful to consumers of bread because it is toxic and can cause abdominal pain, diarrhea, nausea, vomiting, kidney failure, oligonuria, anuria, deafness, vertigo, hypotension, depression of the central nervous system, thrombocytopenia and cancer with other related health problems $[5,6]$. In addition it affects the nutritional quality of bread by degrading its vitamins and essential fatty acid content of flour [3]

Table 2: Concentration of potassium bromate $(\mu \mathrm{g} / \mathrm{g})$ in wheat flour samples

\begin{tabular}{|l|l|}
\hline Wheat flour samples & potassium bromate $(\mu \mathrm{g} / \mathrm{g})$ \\
\hline $01-2137$ & $0.83 \pm 0.01^{\mathrm{a}}$ \\
\hline $01-5189$ & $0.86 \pm 0.01^{\mathrm{a}}$ \\
\hline $01-1007$ & $1.23 \pm 0.01^{\mathrm{b}}$ \\
\hline $01-74883$ & $1.42 \pm 0.01^{\mathrm{b}}$ \\
\hline
\end{tabular}

Results are expressed as meant standard deviation of three observations. Values with similar alphabet do not show significant differences at $\mathrm{p}<0.05$

For the analysis of the hydrocyanic acid contents of the samples, hydrocyanic acid (HCN) released during hydrolysis of the cyanogenic glycosides when it reacts with picric acid was quantified .The hydrocyanic acid contents of the bread and flour samples analyzed were in the range 1.510 to $3.676 \mathrm{mg} / 1000 \mathrm{~g}$ and 0.706 to $1.054 \mathrm{mg} / 1000 \mathrm{~g}$ respectively(Tables 3 and 4). The result showed a low hydrocyanic acid content compare with the observation of Ekop et al. [17]. There was a significant difference $(\mathrm{P} \leq 0.05)$ between the hydrocyanic acid content of bread sample with lowest hydrocyanic acid content and flour with lowest hydrocyanic acid content .This same relationship was observed with samples with highest concentration in each group(Tables 3 and 4) . This suggest that the bakeries in the study area must have probably added another substance containing hydrocyanic acid or cyanogenic glucoside of which the commonest in this area is cassava flour to enhance their profit and reduced the cost of production. The toxic effect of cyanogenic glycosides in food is linked to the hydrocyanic acid $(\mathrm{HCN})$ released during the hydrolysis of cyanogenic glucosides[11,12,13], this leads to inhibition of cellular oxidation and the activity of vitamin $\mathrm{K}$ dependent carboxylase of the liver in addition to exacerbate goitre, cretinism, nausea, dizziness, stomach pains, weakness, headache, diarrhea , paralysis, neurological disorders, Tropical Ataxic Neuropathy (TAN), stunting of children and occasionally death associated to its consumption in large quantity through food $[8,9,10]$. Consumption of these bread samples however, will not lead to the lethal dose of $35 \mathrm{mg}$ hydrocyanic acid per $\mathrm{kg}$ body weight reported by Eneobong[19],because the consumers consume far lower quantity of bread than the quantity that can give this dose, in addition to this, the body has a way of detoxifying small doses of cyanide in food by converting it to thiocyanide, which is excreted in the urine[17] 
Table 3: Concentration of hydrocyanic acid $(\mathrm{mg} / 1000 \mathrm{~g})$ in bread samples

\begin{tabular}{|c|c|}
\hline Bread samples & $\begin{array}{c}\text { Cyanide } \\
(\mathrm{mg} / 1000 \mathrm{~g})\end{array}$ \\
\hline A. & $1.628 \pm 0.01$ \\
\hline B. & $2.291 \pm 0.37$ \\
\hline C. & $2.078 \pm 0.22$ \\
\hline D. & $1.709 \pm 0.15$ \\
\hline E. & $2.623 \pm 0.01$ \\
\hline F. & $1.510 \pm 0.29^{\mathrm{a}}$ \\
\hline G. & $3.433 \pm 0.51$ \\
\hline H. & $1.849 \pm 0.07$ \\
\hline I. & $2.696 \pm 0.88$ \\
\hline J. & $2.505 \pm 0.01$ \\
\hline K. & $1.680 \pm 0.67$ \\
\hline L. & $1.952 \pm 0.01$ \\
\hline M. & $1.849 \pm 0.08$ \\
\hline N. & $3.676 \pm 0.32^{\mathrm{b}}$ \\
\hline O. & $1.967 \pm 0.11$ \\
\hline
\end{tabular}

Results are expressed as meant standard deviation of three observations.

$\mathrm{a}=$ significant difference at $\mathrm{p}<0.05$ compare with wheat flour sample with lowest hydrocyanic acid content. $\mathrm{b}=$ significant difference at $\mathrm{p}<0.05$ compare with wheat flour sample with highest hydrocyanic acid content

Table 4: Concentration of hydrocyanic acid $(\mathrm{mg} / 1000 \mathrm{~g})$ in wheat flour samples

\begin{tabular}{|l|l|}
\hline Wheat flour samples & Cyanide Concentration $(\mathrm{mg} / 1000 \mathrm{~g})$ \\
\hline $01-2137$ & $1.059 \pm 0.014$ \\
\hline $01-5189$ & $1.498 \pm 0.325^{\mathrm{b}}$ \\
\hline $01-1007$ & $1.054 \pm 0.205$ \\
\hline $01-74883$ & $0.706 \pm 0.007^{\mathrm{a}}$ \\
\hline
\end{tabular}

Results are expressed as meant standard deviation of three observations. $a=$ significant difference at $\mathrm{p}<0.05$ compare with bread sample with lowest hydrocyanic acid content. $b=$ significant difference at $p<0.05$ compare with bread sample with highest hydrocyanic acid content.

\section{Conclusion}

The results showed that all the loaves of bread and wheat flour brands analysed contained potassium bromate in high quantity above safe level for human consumption and various amount of hydrocyanic acid which however, will not lead to the lethal dose of $35 \mathrm{mg}$ hydrocyanic acid per $\mathrm{kg}$ body. Therefore, there is need for continuous surveillance and enforcement of the ban on use of potassium bromate in baking industry in this study area by the regulatory agency.

\section{Reference}

[1] B. Maziya-Dixon, I.O. Akinyele, E.B. Oguntona, S. Nokoe, R.A. Sanusi, E. Harris, Nigeria food consumption and nutritional survey 2001-2003. IITA, Ibadan, 2004, 67.

[2] Magomya A.M, G.G Yebpella, , U.U Udiba H.S Amos M.S Latayo(2013) Potassium Bromate and Heavy Metal Content of Selected Bread Samples Produced in Zaria, Nigeria International Journal of Science and Technology ,2 (2),2013,232-237

[3] M.O. Emeje, S.I. Ofoefule, A.C. Nnaji, A.U. Ofoefule and S.A.Brown (2010). Assessment of bread safety in Nigeria: Quantitative determination of potassium bromate and lead. African Journal of Food Science, 4(6), 2010, 394 - 397.

[4] M. Nakamura, T. Murakami, K.Himata ,S. Hosoya and Y.Yamada (2006). Effects of reducing agents and baking conditions on potassium bromate in bread. Cereal Foods World. (51), 2006, 69-75

[5] Atkins DP (1993) Potassium Bromate in Bread. Index to MAFF-UK Food surveillance Information sheets.

[6] Y. Watson, Material safety data sheet: potassium bromate (Mallinckrodt baker Inc. New Jersey, 2000).

[7] B. Nambisan, Cyanogenesis in cassava. In WM Roca, AM Thro, eds, Proceedings of the First International Scientific Meeting of the Cassava Biotechnology Network, Centro Internacional Agricultura Tropical, Cali, Colombia, 1993,424-427

[8] A.O. Onabolu., O.S. Oluwole and M. Bokanga, 2002. Loss of residual cyanogens in a cassava food during short-term storage. Int. J. Food Sci. Nutr.,(53),2002, 343-349.

[9] O.S.A. Oluwole, A.O. Onabolu, I.A. Cotgreave, H. Rosling, A. Persson and H. Link, Incidence of ataxic polyneuropathy and its relationship to exposure to cyanide in a Nigerian community. J. Neurol. Neurosurgery Psychiatry (74), 2003, 1412-1416.

[10] K. Stephenson, R. Amthor, S. Mallowa, R. Nungo, B. Maziya-Dixon and S. Gichuki, 2010. Consuming cassava as a staple food places children 2-5 years old at risk for inadequate protein intake, an observational study in Kenya and Nigeria. Nutr. J., (26), 2010, $1-9$.

[11] J.H. Bradbury and W.D. Holloway, Chemistry of tropical roots: significance for nutrition and agriculture in the Pacific. Canberra, Australia: Australian Centre for International Agricultural Research, 1988:102-104.

[12] P. Nicholls, and T Soulimane, The Mixed Valence State of the Oxidase Binuclear Centre: How Thermus thermophilus Cytochrome ba3 Differs from Classical ba3 in the Aerobic Steady State and When Inhibited by Cyanide. Biochem. Biophys. Acta, 1655(1-3), 2004, 381-387. [13] ] E.A. Uyo, O.Udensi, V. Natui And I.Urua, Effect of different processing methods on cyanide content of garri from four cultivars of cassava. J. of Food, Agriculture and Environment, 5(3\&4) 2007, 105-107.

[14] David P (1976). The chemical Analysis of Foods 7th Ed. Longman group Ltd, London

[15] I. Onwuka, G.I Food Analysis and Instrumentation. Theory and Practice. (Napthali Prints, 2005),140-146. 
[16] E.O.Ojeka,M.L. Obidiaku and C.Enukorah, Spectrophotometric determination of bromate in bread by oxidation of dyes. Journal of Applied Science Environmental Management. 10 (3), 2006 43-46.

[17] A.S. Ekop, I.B.Obot and E.N.Ikpatt (2008). Anti-Nutritional Factors and Potassium Bromate Content in Bread and Flour Samples in Uyo Metropolis, Nigerian E-J Chem. 5(4),2008 736-741.

[18] L.A. Alli, M. M. Nwegbu, B. I. Inyang, K. C. Nwachukwu, J. O. Ogedengbe, O. Onaadepo, M. A. Jamda, G.A. Akintan, S. O. Ibrahim and E. A. Onifade(2013).Determination of Potassium Bromate content in Selected Bread Samples in Gwagwalada, AbujaNigeria. Int J Health Nutr., 4(1),2013 15-20

[19] Eneobong H N, Eating Right (2001)(A Nutrition Guide), (Zoometer Print Communications Ltd. Nigeria,2001) 